\title{
Study on the Properties of an Ecotype Mortar with Rice Husks and Sisal Fibers
}

\author{
Xiaofan Liu $(\mathbb{D}$, Jixiang Li, Fengyun Li, Junguang Wang, and Haijun Lu \\ School of Civil Engineering and Architecture, Wuhan Polytechnic University, Wuhan 430023, China \\ Correspondence should be addressed to Xiaofan Liu; hnsfine@163.com
}

Received 26 February 2021; Revised 16 April 2021; Accepted 24 April 2021; Published 5 May 2021

Academic Editor: Xianming Shi

Copyright (C) 2021 Xiaofan Liu et al. This is an open access article distributed under the Creative Commons Attribution License, which permits unrestricted use, distribution, and reproduction in any medium, provided the original work is properly cited.

\begin{abstract}
Adding plant fibers such as rice husks or sisals to the mortar is one of the main methods to reuse the agricultural wastes and reduce the energy consumption of building industry. However, recent research showed some limitation of the mortar mixed with plant fibers. In this paper, sisal fibers and rice husks were added together into cement mortar to investigate its mechanical properties and the optimum mixture ratio of sisal fiber and rice husk by mix ratio test and orthogonal test. The microstructure of the sisal fiber was observed using scanning electron microscopy (SEM) to understand how the properties of the mortar were affected. Results showed that adding sisal fiber and rice husk into cement mortar significantly improved the mechanic property, anticrack performance, and impermeability of the mortar. The highest compressive strength and flexural strength can reach $17.1 \mathrm{MPa}$ and 3.3 MPa. The area of early cracks was reduced by $100 \%$, and the maximum seepage pressure was $0.36 \mathrm{MPa}$. The microstructure analysis also indicated that adding rice husk and sisal fiber have a positive effect on the mortar. These results support that adding $0.1 \%$ volume admixture of $16 \mathrm{~mm}$ length sisal fiber with $35 \%$ rice husk into mortar is helpful for engineering application.
\end{abstract}

\section{Introduction}

The rapid slumping of resources is attracting increasing social attention to environmental protection and sustainable development. In China, the energy consumption from building accounts for a large proportion $[1,2]$. Lightweight concrete, which contains rice husk instead of sand, is a wellknown material that can reduce the building energy consumption. The application of this material can not only save resources and protect the environment but also promote the research on reusing rice husk to produce economic benefits $[3,4]$. In the last century, H. F. Porter proposed the concept of fiber concrete. From then on, adding various kinds of fiber to the concrete has become a promising research field to improve the performance of the concrete. Natural plant fibers, such as sunflower, sisal, and bamboo [5-7], are very popular in developing countries due to their low cost and high reproducibility [8]. Many research studies have been done to energy-saving and environment-friendly concrete.

There is a long history of the research studies on adding rice husk to mortar. Sun et al. [9] studied the mechanical properties of mortar prepared from rice husk and cement treated with saturated lime water and tap water. According to their research, the mortar prepared from pretreated rice husk, which were soaked with saturated lime water, was greatly improved in performance. António et al. [10] studied the practical application of new type of rice husk wallboard. Their research studies indicated that the new wallboards prepared with rice husk had a better performance. Morgan et al. [3] studied the application of rice husks as lightweight aggregates in low-cost housing.

Sisal fiber also has a significant effect on improving the mortar performance. Huang et al. [11] added sisal fibers with different amounts of mixture into mortar, indicating that the mechanical properties of cement concrete were obviously improved when the amount of admixture of sisal fibers was $3.5 \mathrm{~kg} / \mathrm{m}^{3}$. Silva et al. [12] studied the bond strength and crack resistance of sisal fibers with different shapes in cement. The bending arch exhibited the highest bond stress and the greatest improvement in crack resistance. Besides, adding sisal fibers was shown to greatly improve the crack resistance of the cement by Balaguru [13]. Even when the amount of admixture of fibers was only $0.1 \%$, the reduction of early cracks was obvious. 
According to previous studies, adding rice husk or sisal fiber to mortar can greatly improve the performance of the mortar. However, the low strength and easy cracking feature of the rice husk mortar limited its application. In order to solve this problem, rice husk and sisal fiber were added together into mortar in this study to search for the optimal mixture ratio that could meet the performance requirements of practical projects. The effects of sisal fiber and rice husk on the properties of mortar were discussed, and the mechanism of the hybrid fibers was studied.

\section{Test Scheme}

2.1. Raw Material. The test raw materials are ordinary Portland cement P.O42.5; the maximum particle size of the engineering sand is $2.36 \mathrm{~mm}$ with modulus coefficient of 2.1; the rice husk is from Hubei Province, and its physical properties are shown in Table 1. The lengths of the sisal fibers are $8 \mathrm{~mm}, 12 \mathrm{~mm}$, and $16 \mathrm{~mm}$, respectively. Physical properties of raw material are shown in Tables 1 and 2 .

\subsection{Mixture Ratio of Test Mortar and Specimen Forming.} The mixture ratios of test mortar are shown in Table 3. Sisal fiber's length of $8 \mathrm{~mm}, 12 \mathrm{~mm}$, and $16 \mathrm{~mm}$ with volume admixture of $0.10 \%, 0.15 \%$, and $0.20 \%$ are tested. The replacement rates of rice husk volume are $35 \%, 40 \%$, and $45 \%$. Because the volume of mortar is mainly composed of sands, the replacement of sands is the same volume of rice husk. Moreover, rice husk has high water absorption property; a relatively high water to cement ration was used to ensure the working performance of mixing mortar.

Sisal fiber is easy to agglomerate when mixed into cement-based materials, which will result in uneven fiber distribution. In order to ensure the uniformity, continuity, and good workability of the material, after many attempts, the technological mixing process of sisal fiber rice husk mortar is formulated. Pour the sand and rice husk into the blender and keep stirring. Sisal fiber is added during stirring. Cement and water are added together and stirred in reverse direction for 2 minute. After mixing, the material is divided into three layers to cover the specimen mold, and a vibrator with the diameter of about $2 \mathrm{~cm}$ is used to slightly insert the vibrator layer by layer for 20 second. After smoothing, gently vibrate with both hands for 20 times and then rest. This process can effectively avoid the phenomenon of uneven mixing and floating of rice husk.

\subsection{Test Methods}

2.3.1. Compression Test. The size of sisal fiber husk mortar compression specimen is $70.7 \mathrm{~mm} \times 70.7 \mathrm{~mm} \times 70.7 \mathrm{~mm}$. The specimens were loaded after 28 days of curing. The test was carried out in accordance with the requirements of JGJT70-2009 [14], using miniature controlled electronic universal testing machine. The loading device and the situation of the specimen are shown in Figure 1.
2.3.2. Flexural Test. The sisal fiber husk mortar flexural test specimen is a prism of $100 \mathrm{~mm} \times 100 \mathrm{~mm} \times 400 \mathrm{~mm}$. The test was carried out in accordance with the requirements of GB/ T50081-2002) [15], using miniature controlled electronic universal testing machine, as shown in Figure 2.

\subsubsection{Early Plastic Shrinkage Crack Test of Sisal Fiber Rice} Husk Mortar. The test molds are shown in Figure 3. The displacement of mortar periphery is restrained by the steel frame and steel bolt. Internal mortar shrinkage may produce cracks. The test was carried out in accordance with the requirements of CECS38:2004 [16].

\subsubsection{Antipenetrability Performance Test of Sisal Fiber Rice} Husk Mortar. The test was carried out in accordance with the requirements of JGJ-T70-2009 [14]. Six specimens of sisal fiber rice husk mortar in each group were prepared to carry the antipenetrability performance test. The location form of the specimens is shown in Figure 4.

\section{Test Results and Analysis of Sisal Fiber Rice Husk Mortar}

3.1. Mechanical Properties of the Sisal Fiber Rice Husk Mortar. The results of the mechanical test are shown in Table 4. Table 5 and Figures 5 and 6 are the $k$ value calculated results of the compressive strength and flexural strength of the sisal fiber husk mortar, respectively.

It can be seen from Table 4 that the optimal mixture ratio of sisal fiber rice husk mortar for compressive resistance is $0.10 \%$ volume admixture with $8 \mathrm{~mm}$ length of sisal fiber and 35\% rice husk volume replacement rate. The rice husk volume replacement rate has a dominant contribution to compressive strength, while sisal fiber volume admixture shows smaller effect. The contribution from sisal fiber length is the minimum. The optimal mixture ratio of sisal fiber rice husk mortar for flexural strength is $0.10 \%$ volume admixture with $8 \mathrm{~mm}$ length of sisal fiber and 35\% rice husk volume replacement rate. Sisal fiber length has a dominant contribution to flexural strength, while sisal fiber volume admixture shows smaller effect. The contribution from sisal fiber volume is the minimum.

As shown in Figure 5, the compressive strength of mortar decreases with the increase of sisal fiber length and sisal fiber volume admixture. The sisal fiber length exhibits the greatest influence on the compressive strength.

Figure 6 shows that the flexural strength of the mortar decreases with the increasing of volume admixture of the sisal fiber. The increase of the rice husk volume replacement rate also gradually reduces the flexural strength of the mortar. The length of the sisal fiber exerts little influence on the flexural strength. The volume replacement ratio of the rice husk and the sisal fiber admixture has similar effects on the mortar.

Stress failure of cement can be considered to be a process in which the stress expansion of tiny cracks inside the specimen leads to gradual connection of internal cracks until a complete failure [17]. In the compression test, the overlong sisal fibers in the process of specimen compression cannot be completely stressed due to their low stiffness. However, 
Table 1: Physical properties of the rice husk.

\begin{tabular}{lccccc}
\hline Category & Length $(\mathrm{mm})$ & Width $(\mathrm{mm})$ & Density $\left(\mathrm{g} / \mathrm{cm}^{3}\right)$ & Bulk density $\left(\mathrm{g} / \mathrm{cm}^{3}\right)$ & Thermal conductivity $(\mathrm{W} / \mathrm{m} \cdot \mathrm{K})$ \\
\hline Rice husk & $5 \sim 8$ & $2.5 \sim 5$ & 720 & $83 \sim 160$ & $0.084 \sim 0.209$ \\
\hline
\end{tabular}

Table 2: Physical properties of the sisal fiber.

\begin{tabular}{lcccc}
\hline Fiber category & Density $\left(\mathrm{g} / \mathrm{cm}^{3}\right)$ & Elongation $(\%)$ & Tensile strength $(\mathrm{MPa})$ & Tensile elasticity modulus $(\mathrm{GPa})$ \\
\hline Sisal fiber & 1.45 & $2.0 \sim 2.5$ & $511 \sim 635$ & $9.4 \sim 22.0$ \\
\hline
\end{tabular}

TABLE 3: Mixture ratio of test mortar.

\begin{tabular}{|c|c|c|c|c|c|c|c|c|}
\hline Sample & $\begin{array}{c}\text { Sisal fiber } \\
\text { content (\%) }\end{array}$ & $\begin{array}{l}\text { Sisal fiber length } \\
(\mathrm{mm})\end{array}$ & $\begin{array}{l}\text { Sisal fiber quality } \\
(\mathrm{kg})\end{array}$ & $\begin{array}{c}\text { Rice husk } \\
\text { content (\%) }\end{array}$ & $\begin{array}{l}\text { Rice husk quality } \\
(\mathrm{kg})\end{array}$ & $\begin{array}{l}\text { Sand } \\
(\mathrm{kg})\end{array}$ & $\begin{array}{c}\text { Cement } \\
(\mathrm{kg})\end{array}$ & $\begin{array}{c}\text { Water } \\
(\mathrm{kg})\end{array}$ \\
\hline A0 & 0 & - & 0 & 0 & 0 & 1500 & 400 & 300 \\
\hline $\mathrm{A} 1$ & 0.10 & 8 & 1.45 & 35 & 35 & 975 & 400 & 300 \\
\hline $\mathrm{A} 2$ & 0.10 & 12 & 1.45 & 40 & 40 & 900 & 400 & 300 \\
\hline A3 & 0.10 & 16 & 1.45 & 45 & 45 & 825 & 400 & 300 \\
\hline A4 & 0.15 & 8 & 2.18 & 40 & 40 & 900 & 400 & 300 \\
\hline A5 & 0.15 & 12 & 2.18 & 45 & 45 & 825 & 400 & 300 \\
\hline A6 & 0.15 & 16 & 2.18 & 35 & 35 & 975 & 400 & 300 \\
\hline A7 & 0.20 & 8 & 2.90 & 45 & 45 & 825 & 400 & 300 \\
\hline A8 & 0.20 & 12 & 2.90 & 35 & 35 & 975 & 400 & 300 \\
\hline A9 & 0.20 & 16 & 2.90 & 40 & 40 & 900 & 400 & 300 \\
\hline
\end{tabular}

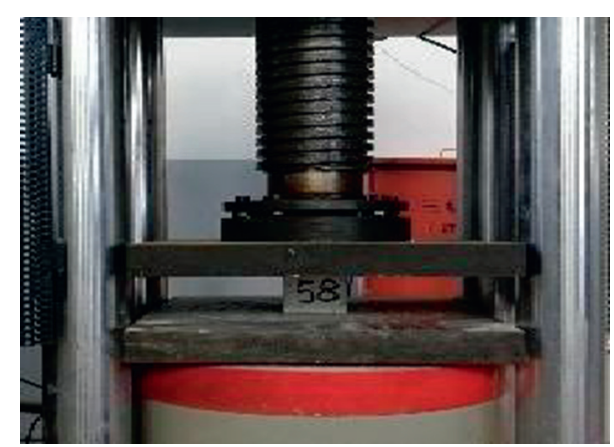

Figure 1: Compression test of sisal fiber husk mortar.

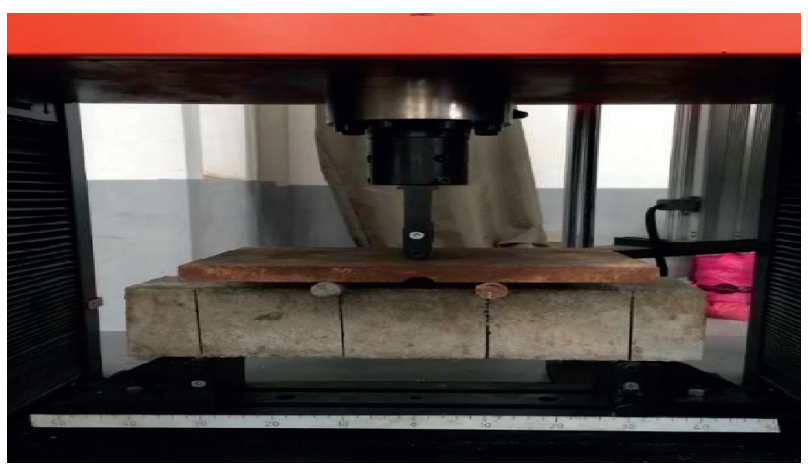

Figure 2: Flexural test of sisal fiber husk.

adding too many sisal fibers may contribute to the failure of producing weak areas in the cement mortar test and therefore limit the strength of cement mortar. In the flexural test, the rice husk and sisal fiber can promote the cement hydration due to their high water retention, which could increase the compactness and integrity of the cement material. However, the water storage capacity of the rice husk

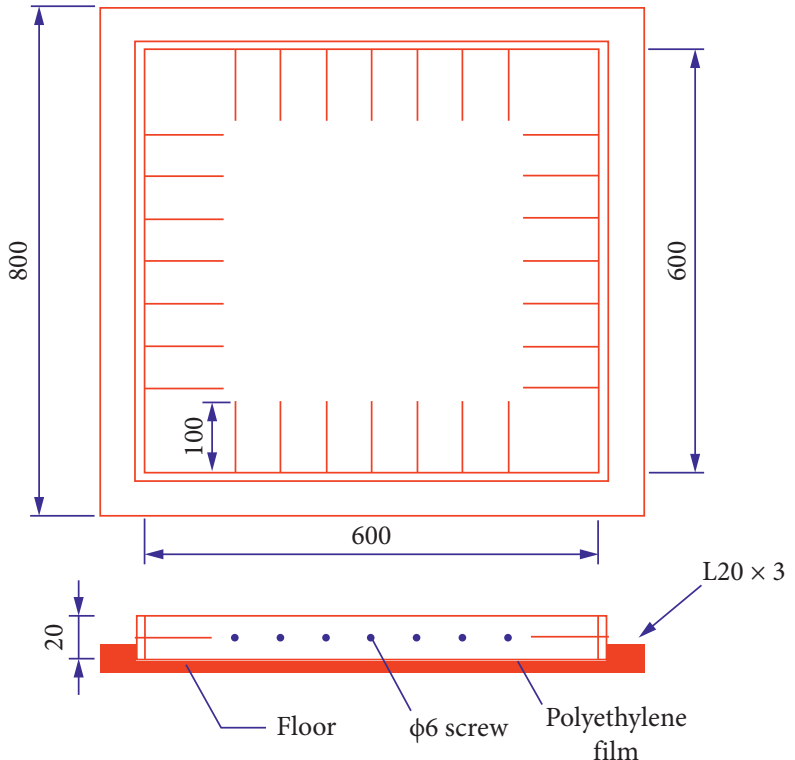

Figure 3: Test mold of early plastic shrinkage crack.

and sisal fiber is inhomogeneous inside the specimen, which results in humidity gradients due to the drying shrinkage of the material itself. When the sisal fiber admixture is increased, the strength of the cement matrix material is lower than that of the cement matrix material with the low volume admixture. The low density of sisal fiber and rice husk will reduce the strength of the cement matrix material when the two materials are overmixed.

3.2. Mechanism Analysis. In 1962, Lyubimove et al. [18] studied mortar on a microscopic scale and proposed the concept of interfacial transition zone (ITZ). They found that 


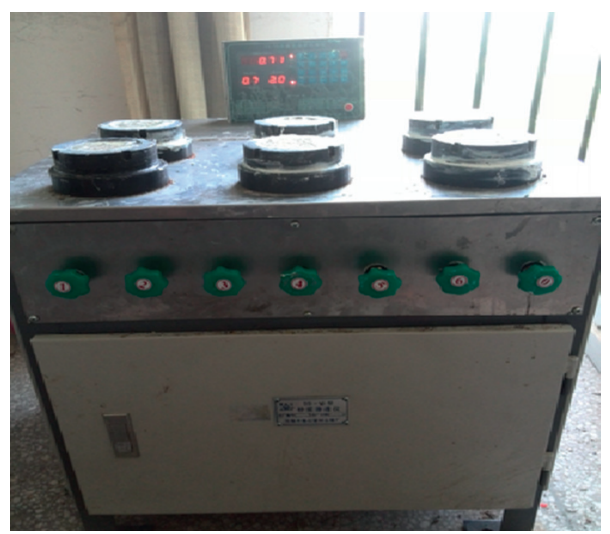

FIGURE 4: Antipenetrability performance test of sisal fiber rice husk mortar.

TABle 4: Experimental results of test blocks.

\begin{tabular}{lcccc}
\hline Sample & Average compressive load $(\mathrm{kN})$ & Compressive strength $(\mathrm{MPa})$ & Average flexural load $(\mathrm{kN})$ & Flexural strength $(\mathrm{MPa})$ \\
\hline A1 & 63.48 & 17.14 & 13.04 & 3.26 \\
A2 & 52.12 & 14.07 & 10.87 & 2.72 \\
A3 & 51.29 & 13.85 & 10.50 & 2.63 \\
A4 & 54.67 & 14.77 & 8.60 & 2.15 \\
A5 & 57.41 & 15.51 & 10.20 & 2.55 \\
A6 & 52.21 & 14.09 & 10.88 & 2.72 \\
A7 & 56.31 & 15.21 & 9.58 & 2.15 \\
A8 & 53.38 & 14.41 & 9.68 & 2.28 \\
A9 & 46.23 & 12.48 & & 2.42 \\
\hline
\end{tabular}

TABLE 5: $k$ value of compressive strength and flexural strength.

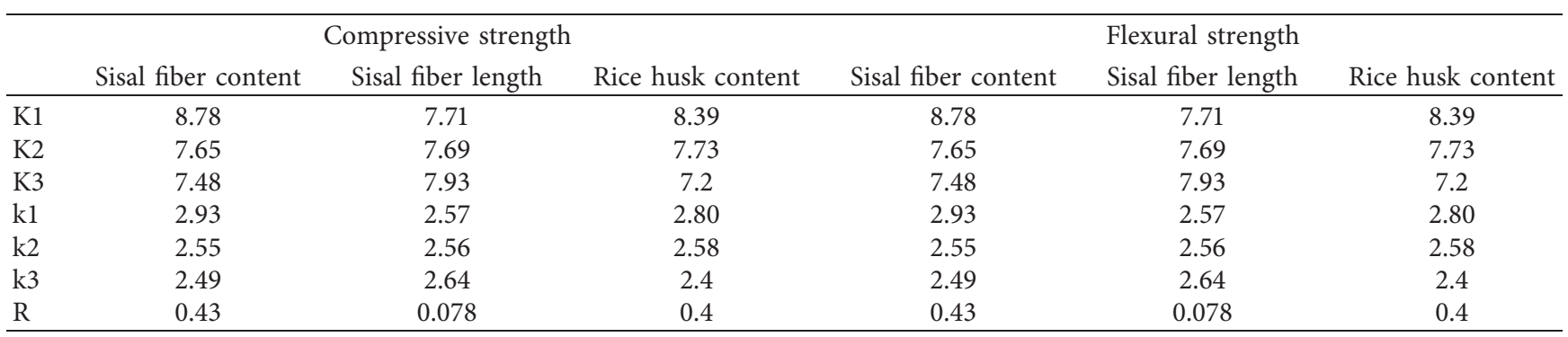

the hardness is minimum near the surface of the aggregate and is increasing towards the direction of the matrix. According to Songshan's model [19] (as shown in Figure 7), the height of interface transition zone [20] is about 15 to $25 \mu \mathrm{m}$.

Measured from the SEM images, as shown in Figures $8(\mathrm{a})$ and $8(\mathrm{~b})$, the pore size of rice husk and the pore diameter of the rice husk cross section are larger than that of the interface transition zone. Therefore, the cement slurry will enter the interior of the rice husk through these pores, increasing the friction produced by the mortar and the husk's uneven surface. Furthermore, the cement mortar will enter the pores on the surface of the rice husk, fixing the rice husk on the surface as the "nail plate," thus forming a hardened cement adhere to rice husk structure (as shown in Figures $8(\mathrm{c})$ and $8(\mathrm{~d})$ ).

The hardness gradient of the ITZ can be explained from its formation process. The infiltration of moisture will be blocked at the surface of the aggregate to form a thicker water film. When the water enters the pores, most of the ions with strong diffusion ability during hydration will be combined with the water in the pores to form crystals. Based on these assumptions, an interface area model around the holes in rice husk is presented, as shown in Figure 9. According to the research of $\mathrm{Hu}$ et al. [21], the internal conservation of moisture in rice husk is fully hydrated in the interface area of cement minerals. As a result, the microhardness of the interface area is higher than that of the cement paste matrix. Because the solution concentration between the husk and the cement is different, the interface area transfers to the lower concentration area, which results in higher silicon-calcium ratio in interface area than that of the cement matrix. Due to its internal porous structure, rice husk releases water in the hydration process of cement and internally maintains the structure of the cement matrix.

According to current research, the strengthening effect of the fiber in the cement matrix mainly includes the following aspects [22]: (1) improving the ductility of the mortar 


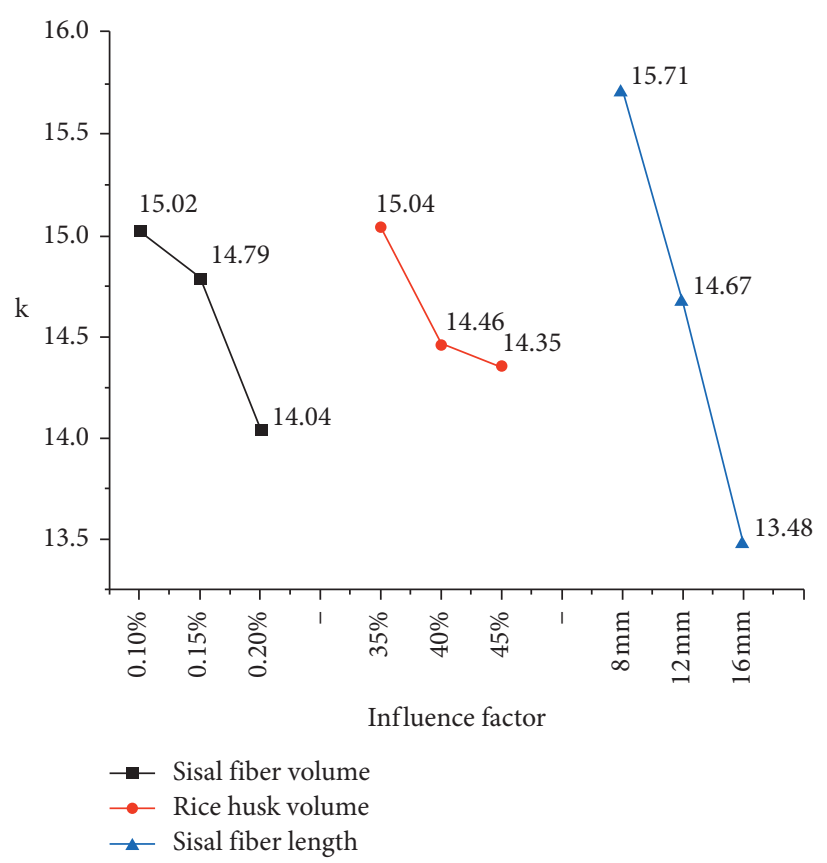

FIgURE 5: $k$ value diagram of the compressive strength.

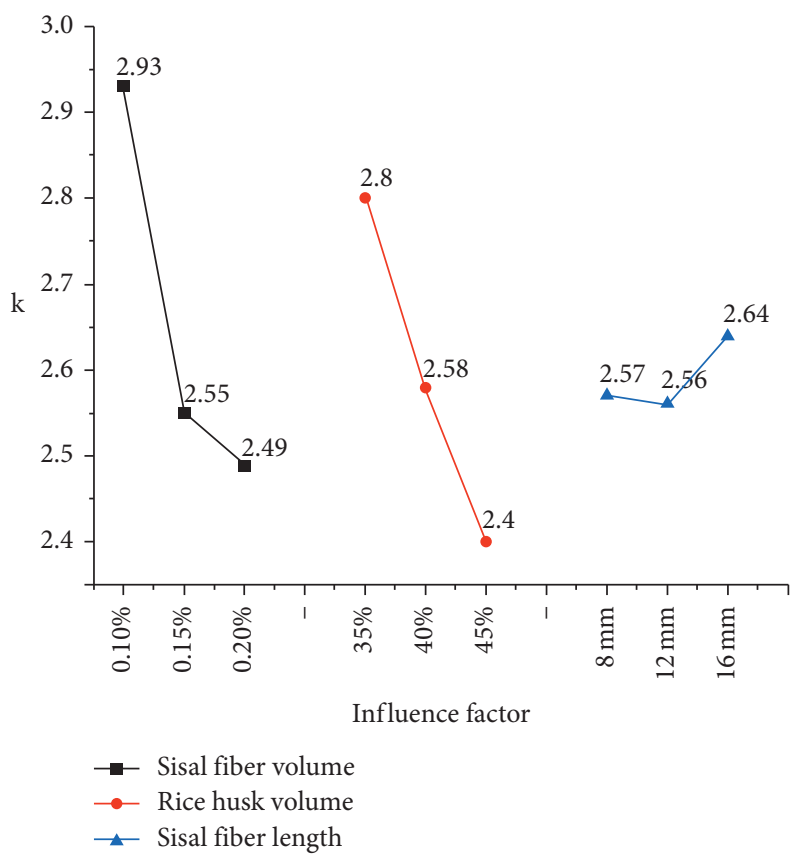

Figure 6: $k$ value diagram of the flexural strength.

matrix, thereby effectively reducing its brittleness and improving its toughness, (2) improving the stress level of cement mortar, and (3) reducing the sedimentation of aggregates. The failure stage of the mortar is divided into two types: mortar failure and hard cement ingredient failure. However, in these two kinds of failure, adding sisal fiber, which has high elastic modulus, high extension strength, and high ultimate deformation property, can disperse parts of the internal force and thereby prevent the failure of the mortar. In the process of the crack expansion, there is the third failure stage of sisal fiber concrete: sisal fiber pull-out failure. During the failure stage of the mortar, the interface between sand and hardened cement be disintegrated and destroyed ultimately. In this process, the sisal fiber plays a reinforcing role which slows down the expansion of cracks. During the failure of hardened cement slurry, macroscopic cracks appear and grow significantly. A large number of sisal fibers can slow down the propagation process of the cracks. In the pulling out stage of sisal fiber and macrocrack expansion, due to the retardation of the sisal fiber, the 


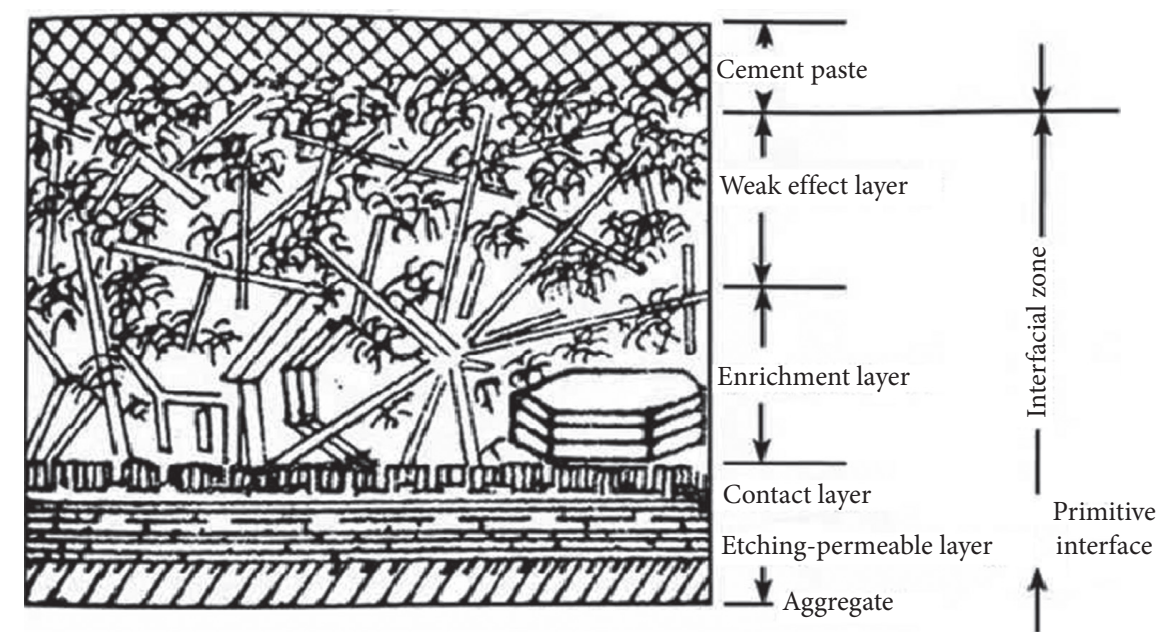

Figure 7: Songshan Jie's model.

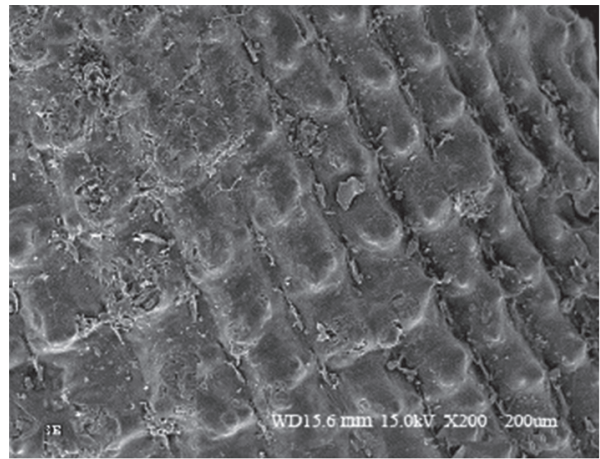

(a)

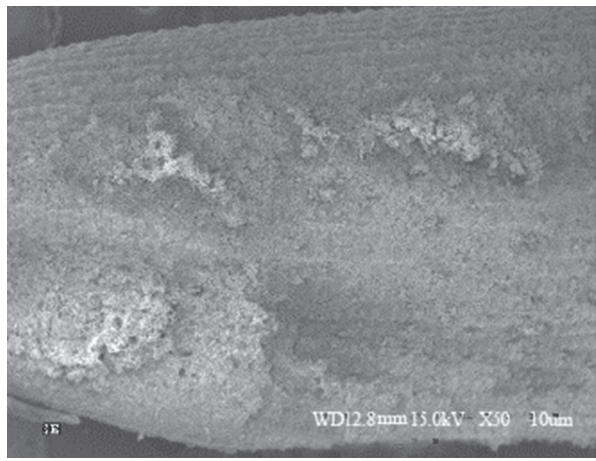

(c)

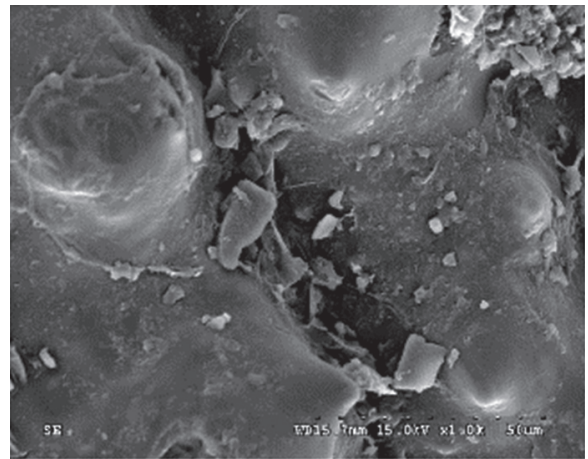

(b)

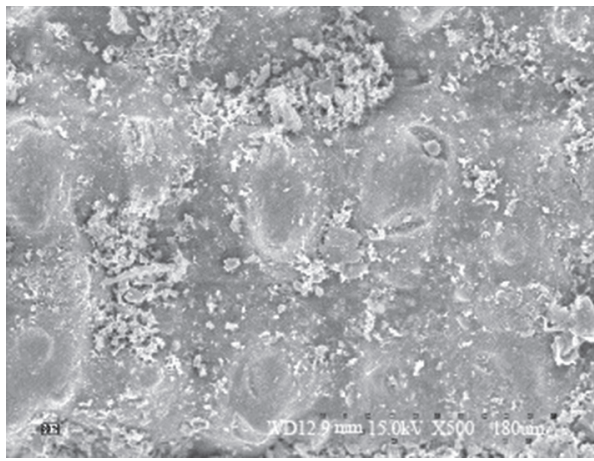

(d)

FIgURE 8: SEM of rice husk mortar surface. (a) Rice husk in mortar magnified 100 times. (b) Rice husk in mortar magnified 1000 times. (c) Rice husk in mortar magnified 50 times. (d) Rice husk in mortar magnified 500 times.

expansion speed becomes slower. However, in this situation, the construction degenerates faster. The bond between the sisal fiber and hardened cement gradually weakens, until the sisal fibers are pulled out and the final components are completely destroyed.

There is also a fiber spacing theory represented by Romualdi and Batson [23]. Based on the fracture mechanics, the sisal fiber is used as a constraint of cracks to explain the fiber spacing theory formed by the crack enhancement. When the fiber length is relatively short, the larger the fiber volume per unit volume is, the smaller the average fiber spacing is. The compressive strength reaches its maximum when the average fiber spacing reaches the optimal fiber spacing. When the fiber length is relatively long, the volume ratio of the fibers is relatively small. When the average spacing of the fibers increases beyond the optimum fiber spacing, the strength enhancement effect of the fiber will be weakened. Figures $10(a)$ and 10(b) show the interface area between the sisal fiber and the cement mortar. The sisal fibers are distributed in the cement mortar being closely 


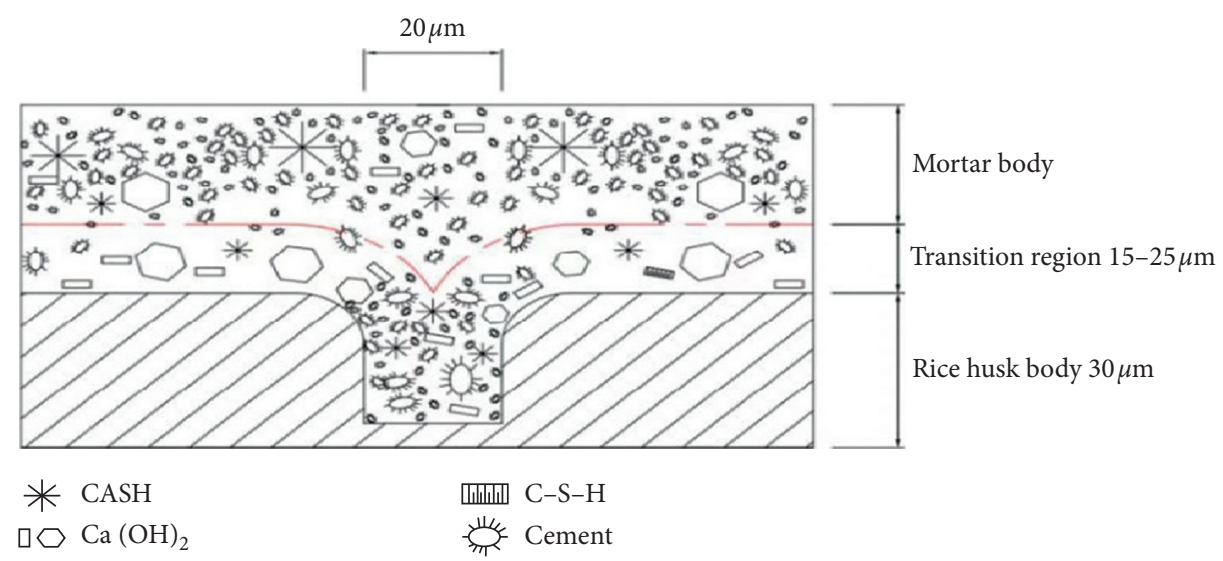

FIGURE 9: Interface area model with the holes in rice husk.

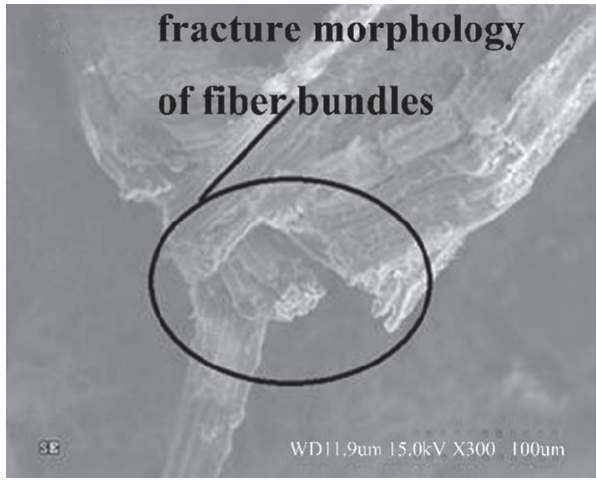

(a)

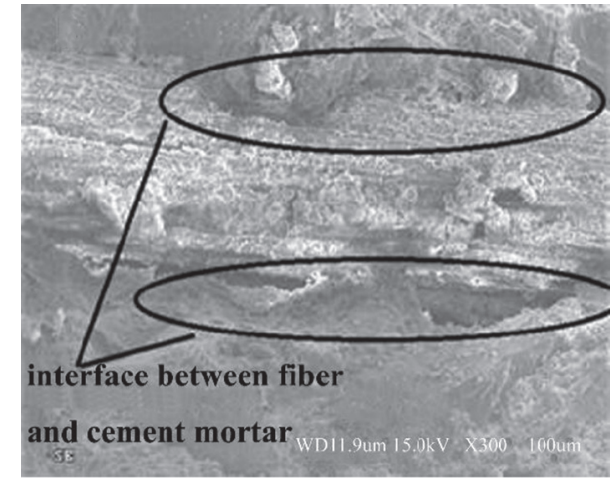

(b)

Figure 10: Interface area of the sisal fiber and the cement mortar.

wrapped, filling up the internal gaps, which effectively make up for the defects of the cement mortar. Adding sisal fibers into the cement mortar of brittle material with internal defects can greatly reduce the size of the internal detects and form a compact structure to improve the performance.

\subsection{Test Results and Analysis of Early Plastic Shrinkage Crack} Performance and Impermeability. Test results of early plastic shrinkage crack performance and impermeability are shown in Table 6. A0 is the pure mortar specimen. Figure 11 shows the $k$ value diagram of factors affecting crack area. Figure 12 shows the $k$ value diagram of the factors affecting the maximum seepage pressure. Figures 13-15 show the crack distribution map of typical specimens.

As shown in Table 6, the early crack area of mortar blocks has been significantly reduced in the samples with sisal fiber and rice husk. The reduction coefficients are above 94\%. Conclusion can be drawn from Figure 11 that the admixture amount of sisal fiber has a dominant contribution to the crack area, while the length of sisal fiber contributes the least. The optimal mixture ratio of crack resistance is $0.10 \% 16 \mathrm{~mm}$ sisal fiber volume admixture and $35 \%$ rice husk volume replacement rate.

According to the $k$ value in Figure 12, the admixture amount of sisal fiber affects the antipermeability property most, while the length of sisal fiber affects least. The optimal mixture ratio of impermeability is $0.10 \% 16 \mathrm{~mm}$ sisal fiber volume admixture and 35\% rice husk volume replacement rate.

The test results showed in Table 5 indicate that the sisal fiber and rice husk improve the impermeability and crack resistance of mortar significantly. The impermeability and crack resistance of sisal fiber rice husk mortar show a positive correlation: the stronger the impermeability is, the stronger the fission resistance is. After being added into the mortar, the sisal fiber and the rice husk form a closely connected net, which have strong water-locking capacity and ability to prevent the uneven settlement of the aggregate. Therefore, adding sisal fiber, the rice husk is helpful to improve the crack resistance and impermeability. However, adding too much fiber and rice husk into mortar has an opposite effect on the impermeability and anticracking performance: the sisal fiber and rice husk will create excessive "channels" along sisal fiber and rice husk. When the seepage pressure increases, these "channels" will connect with each other and lead to the failure of the specimen. In the SEM image of sisal fiber, cavities can be clearly observed in low density, as shown in Figures 16(a) and 16(b). These cavities are evenly distributed in the mortar and therefore effectively prevent the settlement of the mortar and improve the internal bleeding of the mortar. 
TABLE 6: Experimental results of anticrack performance and impermeability.

\begin{tabular}{lccc}
\hline Sample & Crack area $/ \mathrm{mm}^{2}$ & Fracture reduction factor $(\%)$ & Maximum seepage pressure $(\mathrm{MPa})$ \\
\hline A0 & 3016.33 & & 0.19 \\
A1 & 0 & 100 & 0.36 \\
A2 & 38.68 & 98.72 & 0.33 \\
A3 & 53.36 & 98.23 & 0.35 \\
A4 & 116.81 & 96.13 & 0.23 \\
A5 & 122.36 & 95.94 & 0.22 \\
A6 & 66.61 & 97.79 & 0.24 \\
A7 & 179.85 & 94.04 & 0.17 \\
A8 & 132.14 & 95.62 & 0.21 \\
A9 & 158.34 & 94.75 & 0.19 \\
\hline
\end{tabular}

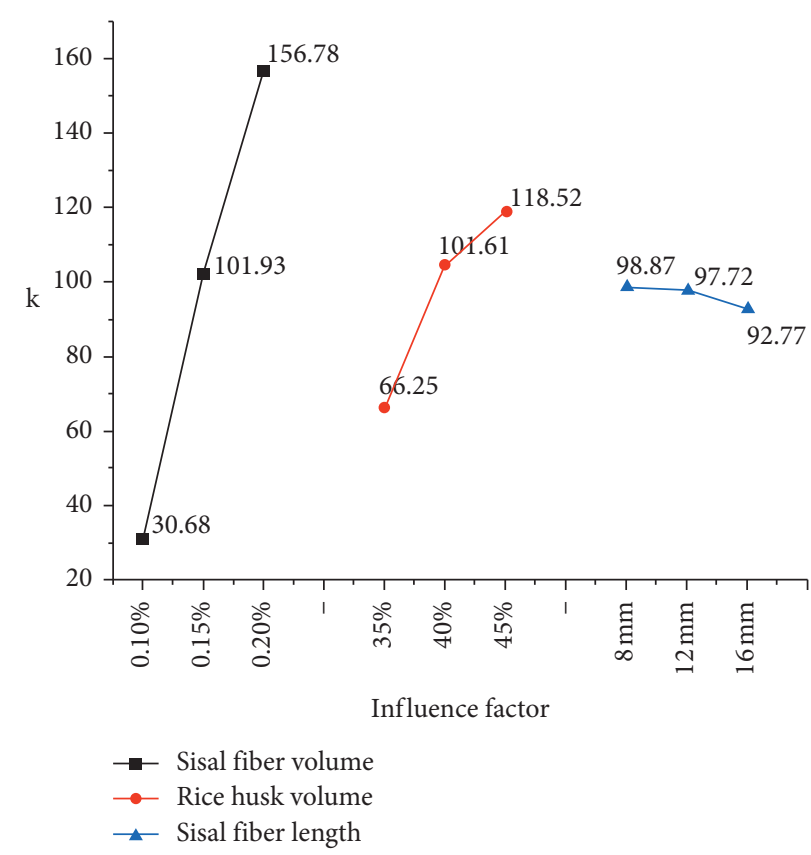

FIgURE 11: The $k$ value diagram of factors affecting crack area.

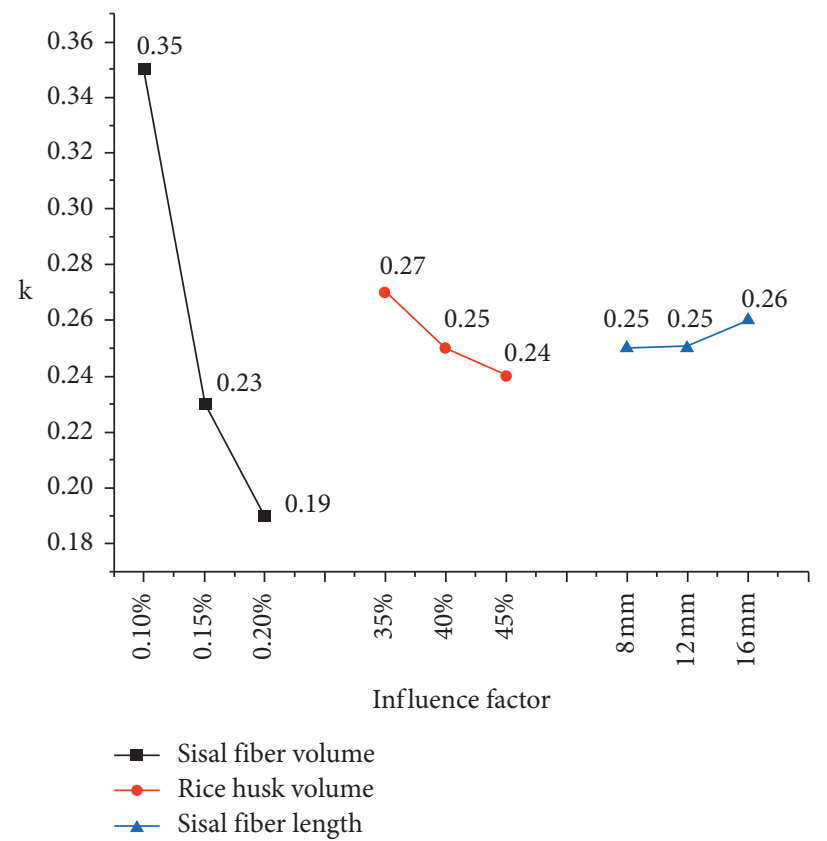

FIgURE 12: The $k$ value diagram of the factors affecting the maximum seepage pressure. 


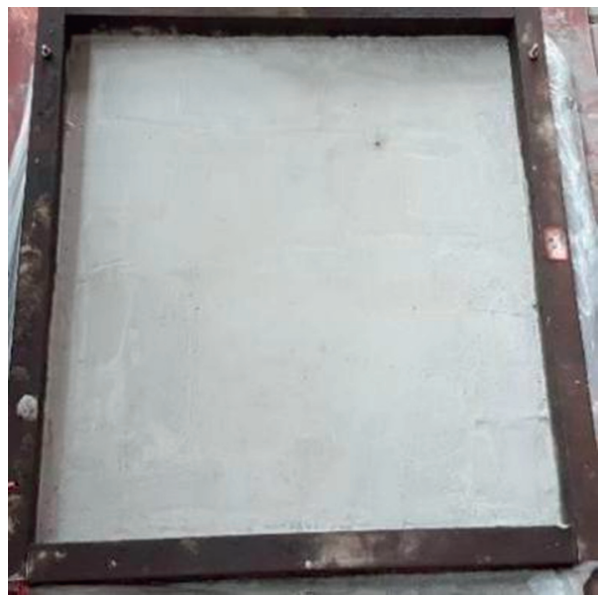

Figure 13: Test A1.

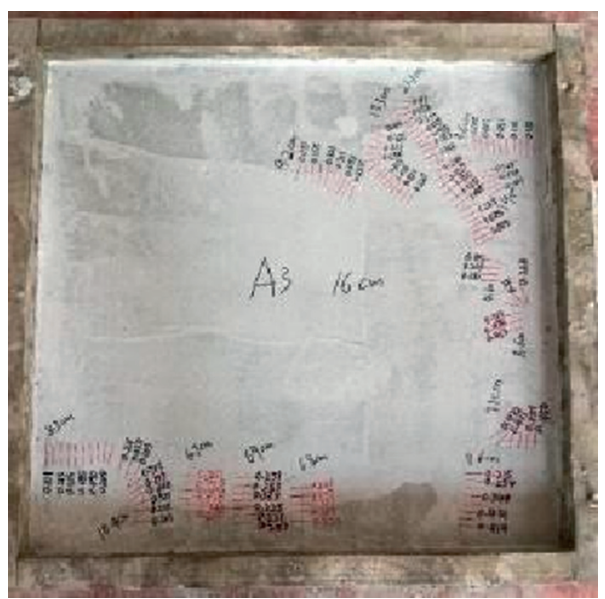

Figure 14: Test A3.

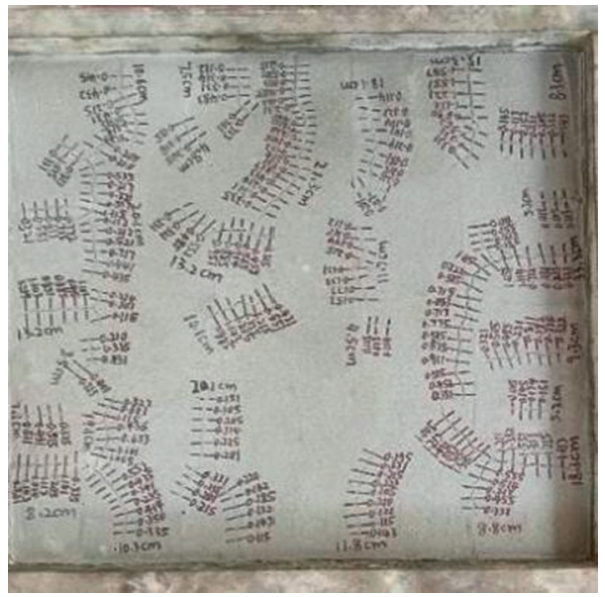

Figure 15: Test A4. 


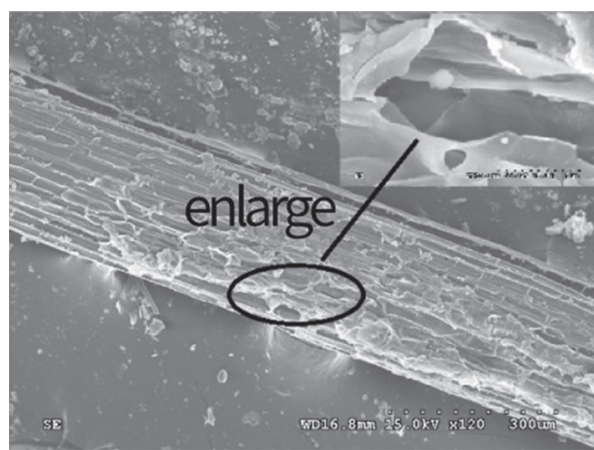

(a)

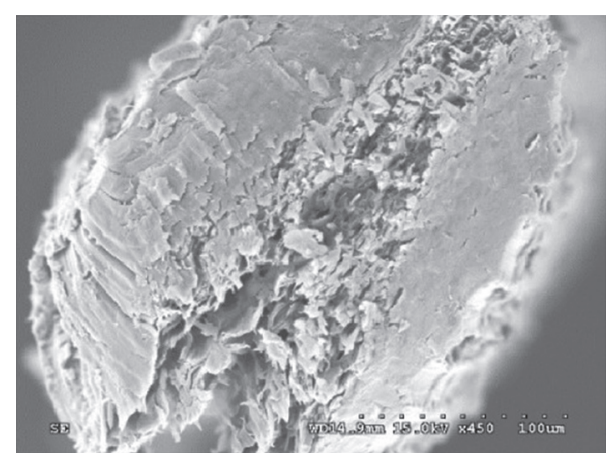

(b)

Figure 16: Cavities in the mortar created by too many fibers.

\section{Conclusion}

In this paper, the effects of sisal fiber and rice husk on mechanical properties, early crack shrinkage, and impermeability of cement mortar were studied. The following conclusions were obtained from the experiments:

(1) The order of influence on compressive strength, from large to small, is the sisal fiber length, sisal fiber content, and rice husk content. The optimal mixture ratio of compressive strength is $0.10 \%$ volume admixture of $8 \mathrm{~mm}$ sisal fiber with $35 \%$ volume admixture of rice husk. The highest compressive strength can reach $17.1 \mathrm{MPa}$.

(2) The order of influence on flexural strength, from large to small, is the sisal fiber content, rice husk content, and sisal fiber length. The optimal mixture ratio is $0.10 \%$ volume admixture of $16 \mathrm{~mm}$ sisal fiber with $35 \%$ rice husk.

(3) The admixture amount of sisal fiber has a dominant contribution to the crack area and antipermeability property, while the length of sisal fiber contributes the least. The optimal mixture ratio of crack resistance and antipermeability property is $0.10 \% 16 \mathrm{~mm}$ sisal fiber volume admixture and 35\% rice husk volume replacement rate. The area of early cracks is reduced by $100 \%$, and the maximum seepage pressure is $0.36 \mathrm{MPa}$.

(4) Microstructure analysis showed that rice husk and sisal fiber release water in hydration process of cement which could improve the mechanical properties of the mortar. The water retention of rice husk and sisal fiber with high elastic modulus can support the interior structure of the mortar and improve its ductility.

\section{Data Availability}

All the data used to support the findings of this study are included within the article.

\section{Conflicts of Interest}

The authors declare that they have no conflicts of interest.

\section{Acknowledgments}

This study was financially supported by the National Natural Science Foundation of China (51474168).

\section{References}

[1] T. Huo, W. Cai, H. Ren et al., "China's building stock estimation and energy intensity analysis," Journal of Cleaner Production, vol. 207, pp. 801-813, 2019.

[2] Y. Lu, "Application analysis and countermeasures of new wall materials," Master's thesis, pp. 9-10, Shandong University, Jinan, China, 2006.

[3] C. Morgan, J.-C. Bénézet, L. Clerc, and E. Garcia-Diaz, "Use of raw rice husk as natural aggregate in a lightweight insulating concrete: an innovative application," Construction and Building Materials, vol. 70, pp. 428-438, 2014.

[4] J. Salas, M. Alvarez, and J. Veras, "Lightweight insulating concretes with rice husk," The International Journal of Cement Composites and Lightweight Concrete, vol. 8, no. 3, pp. 171$180,1986$.

[5] H. Binici, M. Eken, M. Kara, and M. Dolaz, "An environmentfriendly thermal insulation material from sunflower stalk, textile waste and stubble fibers," in Proceedings of the 2013 International Conference on Renewable Energy Research and Applications (ICRERA), October 2013.

[6] H. Jr Savastano, A. Turner, C. Mercer, and W. O. Soboyejo, "Mechanical behavior of cement-based materials reinforced with sisal fibersfibers," Journal of Materials Science, vol. 41, no. 21, pp. 6938-6948, 2006.

[7] R. S. P. Coutts and Y. Ni, "Autoclaved bamboo pulp fibre reinforced cement," Cement and Concrete Composites, vol. 17, no. 2, pp. 99-106, 1995.

[8] T. Yoshio, K. Masaaki, and J. John, "Properties and applications of slag-gypsum construction materials," in Proceedings of the 8th Conference on Inorganic-Bonded Wood and Fiber Composite Materials, pp. 23-25, Boise, ID, USA, 2008.

[9] Z. Sun and L. Zhang, "Effect of rice husk pretreatment process on properties of rice husk mortar," Journal of Tongji University (Natural Science), vol. 43, no. 3, pp. 430-435, 2015.

[10] J. António, A. Tadeu, B. Marques, J. A. S. Almeida, and V. Pinto, "Application of rice husk in the development of new composite boards," Construction and Building Materials, vol. 176, pp. 432-439, 2018.

[11] Q. Huang, F. Qin, F. Ma, and M. Li, "Experimental study on the composites performance of sisal fiber-cement concrete," 
Journal of Guangxi University (National Science Education), vol. 33, no. 1, pp. 27-30, 2008.

[12] F. D. A. Silva, B. Mobasher, C. Soranakom, R. D. T. Filho, and R. D. T. Filho, "Effect of fiber shape and morphology on interfacial bond and cracking behaviors of sisal fiber cement based compositesfiber shape and morphology on interfacial bond and cracking behaviors of sisal fiber cement based composites," Cement and Concrete Composites, vol. 33, no. 8, pp. 814-823, 2011.

[13] P. Balaguru, "Contribution of fibers to crack reduction of cement composites during the initial and final setting period," ACI Materials Journal, vol. 91, no. 3, pp. 280-288, 1994.

[14] Standard for Test Method of Basic Properties of Construction Mortar (JGJ-T70-2009) [S].

[15] Standard for Test Method of Mechanical Property on Ordinary Concrete (GB/T50081-2002) [S].

[16] Technical Specification for Fiber Reinforced Concrete Structures (CECS38:2004) [S].

[17] J. Jiang, J. Li, and W. Jin, Master of Civil Engineering, China Architecture \& Building Press, Beijing, China, 2007.

[18] T. Y. Lyubimova and E. R. Pinus, "Crystallization structure in the contact zone between aggregate and cement in concrete," Colloid Journal, vol. 24, no. 5, pp. 491-498, 1962.

[19] J. Songshan, "Study on interfacial bonding in cement-based composites," Journal of the Chinese Ceramic Society, vol. 11, no. 4, pp. 489-497, 1983.

[20] H. Savastano Jr. and V. Agopyan, "Transition zone studies of vegetable fibre-cement paste composites," Cement and Concrete Composites, vol. 21, no. 1, pp. 49-57, 1999.

[21] S. Hu, "Advanced cement-based composite materials," Science Press, 2009.

[22] P. Soroushian, F. Mirza, and A. Alhozaimy, "Plastic shrinkage cracking of polypropylene fiber reinforced concrete," Materials Journal, vol. 91, no. 3, pp. 280-288, 1994.

[23] J. P. Romualdi and G. B. Batson, "Mechanics of crack arrest in concrete," Journal of the Engineering Mechanics Division, vol. 89, no. 3, pp. 147-168, 1963. 